\title{
Food defense: Perceptions and attitudes of Brazilian dairy companies
}

\author{
Leo O. Lopes, ${ }^{1}$ Ramon Silva,,${ }^{1,2}$ Jonas T. Guimarães, ${ }^{1}$ Nathalia M. Coutinho, ${ }^{1}$ Bruna G. Castro, ${ }^{3}$ \\ Tatiana C. Pimentel, ${ }^{4}$ Maria Carmela K. H. Duarte, ${ }^{1}$ Mônica Q. Freitas, ${ }^{1}$ Erick A. Esmerino, ${ }^{1}$ \\ Anderson S. Sant'Ana, ${ }^{3}$ Márcia C. Silva, ${ }^{2}$ Denise R. P. Azeredo, ${ }^{2}$ Daniel Granato, ${ }^{5}$ and Adriano G. Cruz ${ }^{2 *}$ \\ ${ }^{1}$ Universidade Federal Fluminense (UFF), Faculdade de Medicina Veterinária, 24230-340 Niterói, Brazil \\ ${ }^{2}$ Instituto Federal de Educação, Ciência e Tecnologia do Rio de Janeiro (IFRJ), Departamento de Alimentos, 20270-021, Rio de Janeiro, Brazil \\ ${ }^{3}$ Departament of Food Science, Faculty of Food Engineering, University of Campinas, Campinas, SP - Brazil \\ ${ }^{4}$ Instituto Federal do Paraná (IFPR), Paranavaí, 87703-536, Paraná, Brazil \\ ${ }^{5}$ Food Processing and Quality, Natural Resources Institute Finland (Luke), Tietotie 2, 02150, Espoo, Finland
}

\begin{abstract}
This study aimed to evaluate the perception of Brazilian dairy processors $(\mathrm{n}=31)$ concerning food defense. The results showed that respondents consider the implementation of control procedures related to facilities, products, materials, and individuals as important measures in food defense. The higher agreement rates (strongly agreed + slightly agreed) of the companies in relation to the perception of food defense were $84 \%$ for external security, followed by personnel security $(82 \%)$, generalities (81\%), and internal security $(74 \%)$. Thus, protecting facilities and controlling the traffic flow were considered to be the most important actions under the participants' perspectives. Employee satisfaction and identification of end products and raw materials are also considered relevant in the food defense program. Although food defense is not a formal requirement in Brazilian law, the results show that there is adequate awareness of this topic by the Brazilian dairy companies.
\end{abstract}

Key words: quality control, dairy companies, food safety, food fraud

\section{INTRODUCTION}

In the food industry, quality is related to food safety. According to the Codex Alimentarius (WHO, 2009), food safety is "the assurance that food will not cause harm to the consumer when it is prepared and/or eaten according to its intended use." In this regard, the global food trade is highly interconnected, in which a country's food supply should be internally monitored to avoid contamination, adulteration, and fraudulent activities. For instance, intentional food contamina-

Received February 9, 2020.

Accepted April 13, 2020.

*Corresponding author: food@globo.com tion can negatively affect the food industry in terms of economic losses, both nationally and internationally (Moerman, 2018). The concept of food defense includes activities associated with protecting the food supply against deliberate or intentional food contamination or fraud (Manning, 2019). Food defense refers to intentional food contamination, while food safety refers to unintentional contamination (Bogadi et al., 2016).

Economically motivated adulteration, or food fraud, is the main reason for food defense incidents, and consists of the fraudulent, intentional substitution or addition of a substance in a product for the purpose of increasing the apparent value of the product or reducing the cost of its production (Manning and Soon, 2016). Other motivations include sabotage and terrorism. Sabotage is the intentional adulteration with a view to cause harm, fear, or dread (Manning, 2019), while terrorism is when the violator targets death and serious harm to victims, associated with the publicity of the occurrence (Spink et al., 2019). Fredrickson (2014) reported the relevance of this theme, confirming over 350 malicious contaminations and over 169 incidents of food adulteration aimed at an economic gain. Therefore, food defense activities protect against both food fraud and malicious activities, including terrorism and sabotage (Manning, 2019).

Dairy farming represents one of the most important economic activities in Brazil. According to data from Embrapa, Brazil's milk production reached 35 billion liters/year in 2017 (EMBRAPA, 2018), making it a potential for economically motivated perpetrations and malicious attacks. Recent reports have shown that milk has been a target of fraud, initially aimed to gain volume by adding water and removing the cream. However, new practices have emerged such as the addition of cheese whey, sodium peroxide, calcium hydroxide, salt, sugar, and starch. These intentional actions, motivated by economic gain, can lead to product contamination, revealing the fragility of this productive chain for mali- 
cious attacks (Abrantes et al., 2014). Milk production is expected to grow over the next $10 \mathrm{yr}$ at an annual rate of 2.1 to $2.9 \%$, an increase from 35.3 billion liters in 2018 to 43.4 to 48.1 billion liters, and increase by $28.7 \%$ in milk exports at the end of the period from 2018 to 2028 (Brazil, 2018).

Implementing food defense in the food industry requires companies to be certified in food safety system standards such as those supported by the Global Food Safety Initiative. Although food defense is an inevitable step to improve and strengthen the entire food safety system on a global scale, few countries have adhered to food defense principles in their legal frameworks (Bogadi et al., 2016). Currently, the main programs applied to food defense are CARVER + Shock, which can be used to assess the vulnerabilities within a system or infrastructure to an attack (US FDA, 2009); Threat Assessment and Critical Control Points, which focuses on tampering, intentional adulteration of food, and food defense (BSI, 2017); and Hazard Analysis and Risk-Based Preventive Controls mandated by the US FDA Food Safety Modernization Act, which aims to apply a proactive and systematic approach to the food safety program through the establishment of preventive controls designed to protect the food and the consumer from biological, chemical (including radiological), and physical hazards (US FDA, 2014, 2018). Furthermore, within the United States, there is the Hazard Analysis and Risk-Based Preventative Controls regulation (US FDA, 2015), which aims to protect against economically motivated adulteration, and the Intentional Adulteration Rule, which aims to protect against intentional adulteration that can cause public health harm (such as terrorism and sabotage; US FDA, 2016).

The perception of dairy companies on several food safety topics has been evaluated, such as traceability (Matzembacher et al., 2018) and fraud (Soon et al., 2019). However, there are no reports on the perception concerning the food defense system. Thus, the objective of this study was to evaluate the perception of the food defense system by Brazilian dairy companies.

\section{MATERIALS AND METHODS}

\section{Sampling}

Thirty-one dairy companies $(\mathrm{n}=31)$ that only commercialized dairy products of bovine origin with the federal inspection seal located in several Brazilian states (Rio de Janeiro, Sao Paulo, Minas Gerais, Paraná, Goias, Bahia, Rio Grande do Sul, and Ceará) were studied. The process of choosing companies was based on convenience sampling (Carrillo et al., 2012); the purpose was to obtain a representative sample of the dairy companies in Brazil, and the criteria included companies have the federal inspection seal, which allows a company to commercialize the dairy product along Brazilian territory. From this selection, they were selected randomly in each Brazilian region in a proportion of $30,30,20,10$, and $10 \%$ southeast, south, midwest, north, and northeast regions, respectively, according to their populations.

All dairy companies had at least implemented quality and safety management practices, such as good manufacturing practice and standard sanitizing operating procedures. The study was performed from June to September 2018. The following steps were performed: (1) distribution of a questionnaire via electronic mail to the production sectors or quality assurance, (2) return of the questionnaires, and (3) statistical analysis of the results. The questionnaire contained 39 statements organized into 4 groups as follows: (1) external security (items 1-11), (2) internal security (items 12-21), (3) personnel security (items 22-27), and (4) generalities (items 28-39) (Praia, 2017). Each statement was assessed according to the Likert Scale of 5 points $(1=$ strongly disagree, $3=$ neither agree nor disagree, $5=$ strongly agree). The questionnaires were answered by the individual responsible for the quality control sector of each dairy company.

\section{Statistical Analysis}

Data were analyzed using descriptive statistics (mean and standard deviation) and factor analysis using the principal component analysis method and the varimax rotation method for greater item separation. Factors with eigenvalues higher than 1 were considered relevant. Factor analysis data were examined for normality, collinearity, and outlier distribution. Kaiser-Meyer-Olkin test, Cronbach alpha coefficient, and Bartlett's test for sphericity were used to check the adequacy of the factor analysis (Pacheco et al., 2018).

\section{RESULTS AND DISCUSSION}

Figure 1 shows the results of the food defense questionnaire items in Brazilian dairy processors. If we look at the agreement rate (strongly agree + slightly agree) of the companies for each group in relation to food defense, they perceive external security as the most important (84\%), followed by personnel security $(82 \%)$, generalities (81\%), and internal security $(74 \%)$. These results suggest that the dairy processors understand the concept of food defense as it relates to intentional food contamination (Bogadi et al., 2016) and that the processors likely believe there is a higher chance of somebody outside of the industry to be interested 
in sabotage or terrorism than the internal employees. Furthermore, some studies indicate that the industries have stronger internal controls (e.g., control measures within organization; own staff) compared with external controls (e.g., third-party audits; inspections; Soon et al., 2019).
Respondents believed that external security may allow product safety ( $74 \%$ of respondents strongly agreed, with a score of 5 on the Likert scale). However, $13 \%$ of the respondents neither agreed nor disagreed (score 3), and only 1\% strongly disagreed (score 1). These results are mainly associated with items 1, 2,
(A)

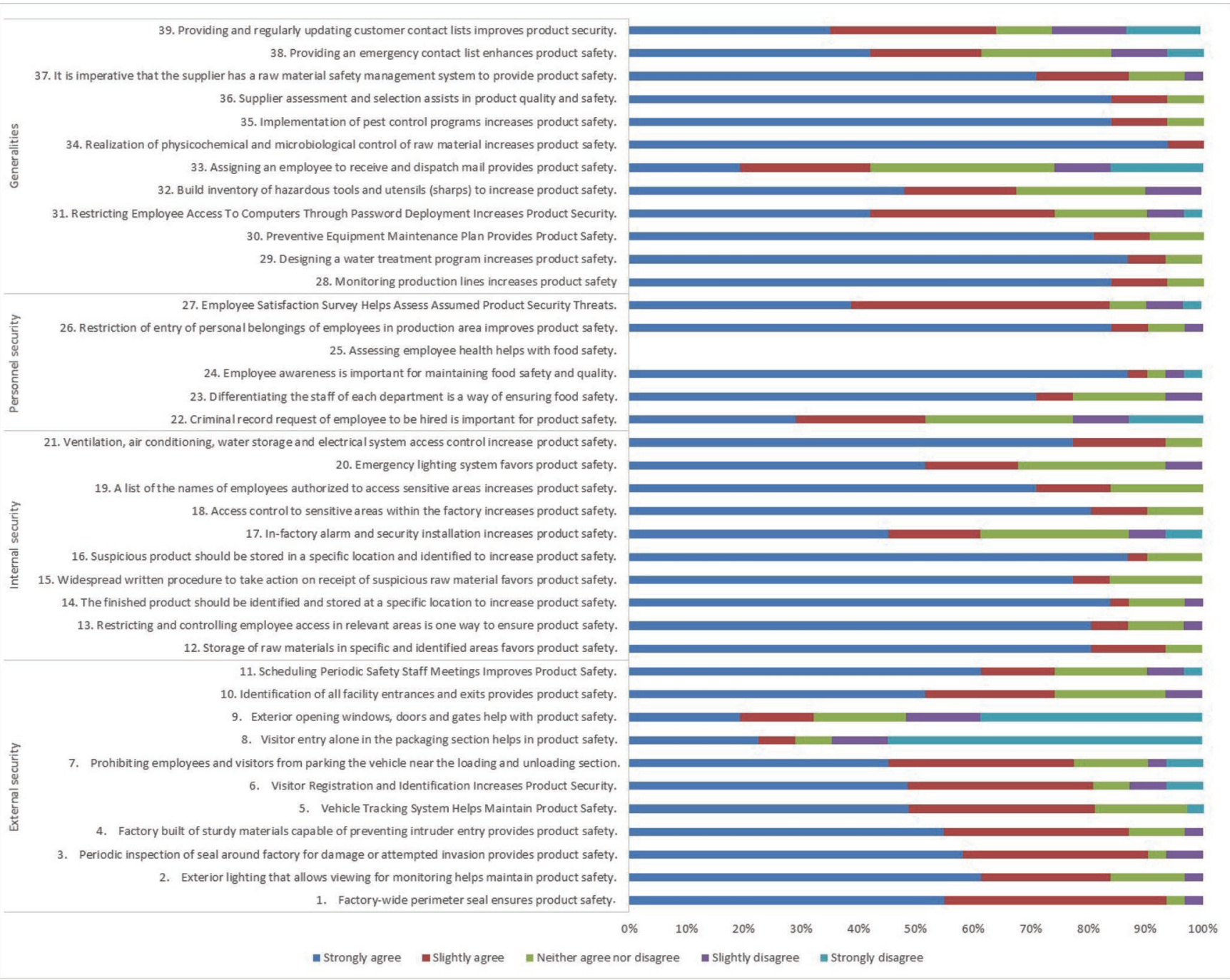

(B)

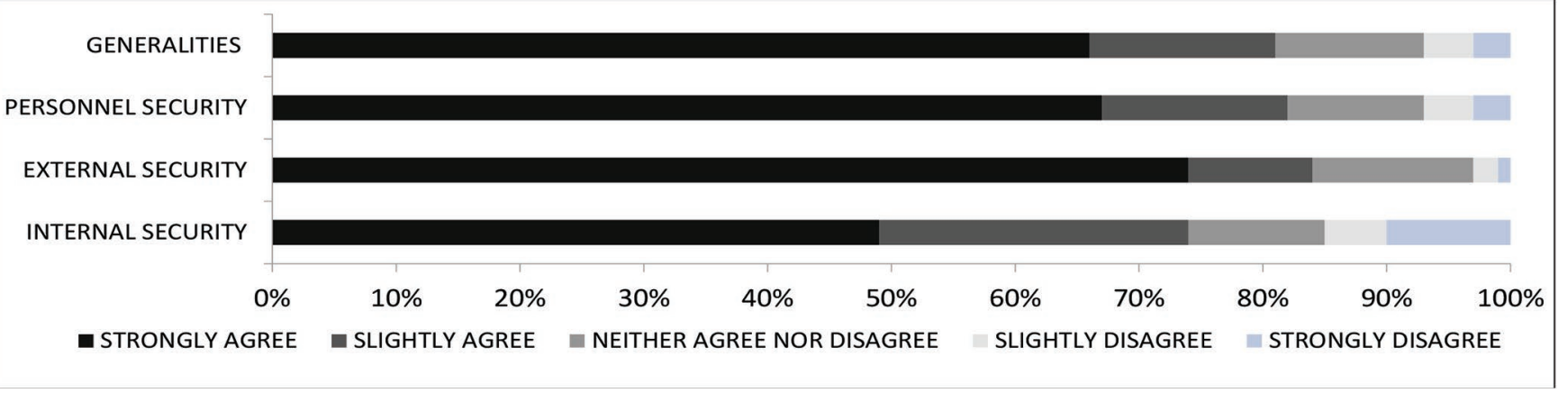

Figure 1. Brazilian dairy processors' perceptions of food defense by (A) items of the Likert scale and (B) categories. 
3 and 4 , which had $>84 \%$ of the responses as scores 4 and 5 (slightly agreed to strongly agreed), suggesting that the dairy processors are mainly worried with the factory-wide perimeter, utilization of exterior lightning, periodic inspection of seal around factory, and factory materials that prevent intruder entry. The outer perimeter is the first protective barrier within an industry, as it protects from environmental contamination and prevents strangers from accessing the facilities (Lelieveld, 2005). One of the simplest steps to reduce the threat is to lock external entryways to facilities and to limit the access inside buildings to only employees (Hennessey and Busta, 2014).

Regarding internal security, most respondents reported that they strongly agreed (score 5) that this group helps to maintain the product safety (49\%). However, $11 \%$ of respondents neither agreed nor disagreed (score 3 ), and $10 \%$ strongly disagreed (score 1 ). These results are mainly associated with items $12,16,18$, and 21 , which had $>90 \%$ of the responses as scores 4 and 5 (slightly agreed to strongly agreed), suggesting that the dairy processors are mainly concerned with the storage of raw materials or suspicious products in specific and identified areas, and access control to sensitive areas, ventilation, air conditioning, water storage, and electrical system. Assuring the control of personnel in those key areas is needed, and different uniforms (i.e., colors) can be an alternative to identify employees in the industry facilities, thus creating a stricter access control (Hennessey and Busta, 2014).

Considering personnel security, most respondents reported that they strongly agreed (score 5) that this group helps to maintain product safety $(67 \%)$. However, $11 \%$ of respondents neither agreed nor disagreed (score 3), and 3\% strongly disagreed (score 1). These results are mainly associated with factors 24 and 26 , which had $>90 \%$ of the responses as scores 4 and 5 (slightly agreed to strongly agreed), suggesting that the dairy processors are mainly concerned about the employee awareness and restriction of personal belongings in production area. To strengthen food defense plans, a food company should consider increasing the awareness of food defense by creating work task activities, comprehensive trainings, and other activities (Betancourt, 2017). In addition, as uniforms can be contamination vehicles, the exchange of uniforms among employees (i.e., from different areas) should not be allowed (USDA, 2008).

Finally, most respondents reported that they strongly agreed (score 5) that the generalities group helps to maintain the product safety $(66 \%)$. However, $12 \%$ of respondents neither agreed nor disagreed (score 3), and $3 \%$ strongly disagreed (score 1 ). These results are mainly associated with items 28 through 30 and 34 through
36 , which had $>90 \%$ of the responses as scores 4 and 5 (slightly agreed to strongly agreed), suggesting that the dairy processors are mainly concerned with monitoring production lines, designing water treatment program, providing maintenance of the preventive equipment, controlling the raw material (by physicochemical and microbiological analyses), pest control, and supplier assessment and selection. The control of raw material and supplier assessment and selection can decrease the risk of external fraud, such as supply of inferior, substituted, or adulterated foods. At the same time, monitoring the production lines can reduce internal food fraud (Soon et al., 2019). Some authors have pointed out that a tool inventory contributes to preventing the risk of physical contamination of food since it may indicate whether the employee has forgotten any object in the production area (Henriques and Fraqueza, 2015).

Factor analysis explained $61.59 \%$ of the data in 2 dimensions, corresponding to $54.14 \%$ in the first dimension (D1) and $7.44 \%$ in the second dimension (D2). Table 1 presents the mean scores, standard deviations, and factor loadings of the statements evaluating the perception of dairy companies on food defense requirements. Cronbach's a coefficient was used to determine the reliability of the scale, and the value of 0.973 indicated that the scale in the present study can be considered of high consistency, as values above 0.6 are considered good (Maciel et al., 2013). The Kaiser-Meyer-Olkin value was 0.672 , indicating a good correlation between variables, as a minimum of 0.5 is usually used as an acceptable limit (Maciel et al., 2013). Finally, Bartlett's test for sphericity showed significance $(P<$ $0.0001)$, suggesting that there are standardized relationships between variables. A statistically significant value in Bartlett's test $(P<0.05)$ indicates that the correlation coefficients between variables are significant enough to continue the analysis (Sobhanifard, 2018).

For communalities, values lower than 0.3 suggest a weak relationship between variables (Rahnama et al., 2017). Of the 39 questionnaire items, 37 were important for the food defense (factors $1-5$ and 8-39, communalities $>0.3$ ), which are associated with external security, internal security, personnel security, and generalities. Nonsignificant statements (communalities $<0.3$, items 6 and 7) were all related to external security, such as controlling access of employees and visitors. Therefore, the dairy processors do not believe that registration and identification of visitors or the prohibition of the employees and visitors from parking vehicles near the loading and unloading section could increase the product safety.

Overall, D1 was positively correlated with items 1,2 , 4, 5, 9 through 14, 16 through 19, 21 through 28, 30, and 32 through 37 . Therefore, topics such as factory- 
Table 1. Mean scores and SD of the statements concerning the perception of Brazilian dairy processors toward food defense

Food defense requirement list

Factorial load ${ }^{1}$

1. Factory-wide perimeter seal ensures product safety.

2. Exterior lighting that allows viewing for monitoring helps maintain product safety.

3. Periodic inspection of seal around factory for damage or attempted invasion provides product safety.

4. Factory built of sturdy materials capable of preventing intruder entry provides product safety.

5. Vehicle tracking system helps maintain product safety.

6. Visitor registration and identification increases product security.

7. Prohibiting employees and visitors from parking the vehicle near the loading and unloading section increases product safety.

8. Visitor entry alone in the packaging section helps in product safety.

9. Exterior opening windows, doors and gates help with product safety.

10. Identification of all facility entrances and exits provides product safety.

11. Scheduling periodic safety staff meetings improves product safety.

12. Storage of raw materials in specific and identified areas favors product safety.

13. Restricting and controlling employee access in relevant areas is one way to ensure product safety.

14. The finished product should be identified and stored at a specific location to increase product safety.

15. Widespread written procedure to take action on receipt of suspicious raw material favors product safety.

16. Suspicious product should be stored in a specific location and identified to increase product safety.

17. In-factory alarm and security installation increases product safety.

18. Access control to sensitive areas within the factory increases product safety.

19. A list of the names of employees authorized to access sensitive areas increases product safety.

20. Emergency lighting system favors product safety.

21. Ventilation, air conditioning, water storage and electrical system access control increase product safety.

22. Criminal record request of employee to be hired is important for product safety.

23. Differentiating the staff of each department is a way of ensuring food safety.

24. Employee awareness is important for maintaining food safety and quality.

25. Assessing employee health helps with food safety.

26. Restriction of entry of personal belongings of employees in production area improves product safety.

27. Employee satisfaction survey helps assess assumed product security threats.

28. Monitoring production lines increases product safety

29. Designing a water treatment program increases product safety.

30. Preventive equipment maintenance plan provides product safety.

31. Restricting employee access to computers through password deployment increases product security.

32. Build inventory of hazardous tools and utensils (sharps) to increase product safety.

33. Assigning an employee to receive and dispatch mail provides product safety.

34. Realization of physicochemical and microbiological control of raw material increases product safety.

35. Implementation of pest control programs increases product safety.

36. Supplier assessment and selection assists in product quality and safety.

37. It is imperative that the supplier has a raw material safety management system to provide product safety.

38. Providing an emergency contact list enhances product safety.

39. Providing and regularly updating customer contact lists improves product security.

\begin{tabular}{|c|c|c|c|}
\hline \multirow[b]{2}{*}{ Mean } & \multirow[b]{2}{*}{ SD } & \multicolumn{2}{|c|}{ Factorial load ${ }^{1}$} \\
\hline & & D1 & D2 \\
\hline 4.45 & 0.72 & $0.699^{*}$ & 0.253 \\
\hline 4.41 & 0.84 & $0.626^{*}$ & 0.474 \\
\hline $4.41^{*}$ & $0.84^{*}$ & $0.527^{*}$ & $0.535^{*}$ \\
\hline $4.38^{*}$ & $0.80^{*}$ & $0.454^{*}$ & $0.332^{*}$ \\
\hline $4.22^{*}$ & $0.94^{*}$ & $0.588^{*}$ & $0.165^{*}$ \\
\hline $4.19^{*}$ & $1.01^{*}$ & $-0.241^{*}$ & $0.188^{*}$ \\
\hline $4.22^{*}$ & $1.05^{*}$ & $-0.149^{*}$ & $0.250^{*}$ \\
\hline $4.25^{*}$ & $1.71^{*}$ & $0.362^{*}$ & $0.469^{*}$ \\
\hline $4.51^{*}$ & $1.58^{*}$ & $0.685^{*}$ & $0.303^{*}$ \\
\hline $4.12^{*}$ & $0.99 *$ & $0.897^{*}$ & $0.308^{*}$ \\
\hline $4.19^{*}$ & $1.13^{*}$ & $0.777^{*}$ & $0.295^{*}$ \\
\hline $4.74^{*}$ & $0.57^{*}$ & $0.854^{*}$ & $0.126^{*}$ \\
\hline $4.64^{*}$ & $0.79^{*}$ & $0.793^{*}$ & $0.396^{*}$ \\
\hline $4.67^{*}$ & $0.79 *$ & $0.907^{*}$ & $0.210^{*}$ \\
\hline $4.61^{*}$ & $0.76^{*}$ & $0.396^{*}$ & $0.711^{*}$ \\
\hline $4.77^{*}$ & $0.61^{*}$ & $0.653^{*}$ & $0.493^{*}$ \\
\hline $3.87^{*}$ & $1.25^{*}$ & $0.708^{*}$ & $0.423^{*}$ \\
\hline $4.71^{*}$ & $0.64^{*}$ & $0.564^{*}$ & $0.415^{*}$ \\
\hline $4.54^{*}$ & $0.76^{*}$ & $0.876^{*}$ & $0.230^{*}$ \\
\hline $4.12^{*}$ & $1.02^{*}$ & $0.154^{*}$ & $0.777^{*}$ \\
\hline $4.71^{*}$ & $0.58^{*}$ & $0.782^{*}$ & $0.242^{*}$ \\
\hline $3.45^{*}$ & $1.36^{*}$ & $0.740^{*}$ & $0.075^{*}$ \\
\hline $4.41^{*}$ & $0.99^{*}$ & $0.947^{*}$ & $0.216^{*}$ \\
\hline $4.67^{*}$ & $0.94^{*}$ & $0.846^{*}$ & $0.263^{*}$ \\
\hline $4.71^{*}$ & $0.73^{*}$ & $0.597^{*}$ & $0.414^{*}$ \\
\hline $4.71^{*}$ & $0.64^{*}$ & $0.852^{*}$ & $0.334^{*}$ \\
\hline $4.09^{*}$ & $1.01^{*}$ & $0.911^{*}$ & $0.224^{*}$ \\
\hline $4.77^{*}$ & $0.56^{*}$ & $0.768^{*}$ & $0.319^{*}$ \\
\hline $4.80^{*}$ & $0.54^{*}$ & $0.212^{*}$ & $0.817^{*}$ \\
\hline $4.71^{*}$ & $0.64^{*}$ & $0.609^{*}$ & $0.464^{*}$ \\
\hline $4.03^{*}$ & $1.08^{*}$ & $0.250^{*}$ & $0.828^{*}$ \\
\hline $4.06^{*}$ & $1.06^{*}$ & $0.645^{*}$ & $0.151^{*}$ \\
\hline $3.19^{*}$ & $1.32^{*}$ & $0.844^{*}$ & $0.287^{*}$ \\
\hline $4.93^{*}$ & $0.25^{*}$ & $0.645^{*}$ & $0.151^{*}$ \\
\hline $4.77^{*}$ & $0.56^{*}$ & $0.844^{*}$ & $0.287^{*}$ \\
\hline 4.77 & $0.56^{*}$ & $0.879^{*}$ & $0.206^{*}$ \\
\hline $4.54^{*}$ & $0.81^{*}$ & $0.754^{*}$ & $0.222^{*}$ \\
\hline $3.8^{*}$ & $1.27^{*}$ & $0.224^{*}$ & $0.748^{*}$ \\
\hline $3.58^{*}$ & $1.14^{*}$ & $0.151^{*}$ & $0.649^{*}$ \\
\hline
\end{tabular}

${ }^{1}$ Results are expressed considering mean and SD in accordance with the Likert scale $(1=$ strongly disagree; $2=$ slightly disagree; $3=$ neither agree nor disagree; $4=$ slightly agree; $5=$ strongly agree). D1, D2 = first and second dimension of the factorial analysis.

*Significant factor loadings in the axis after Varimax rotation.

wide perimeter seal, exterior lighting, identification of all entrances, scheduling of periodic safety staff meetings, adequate storage of raw materials, alarm installation, restriction and control over employee access, and monitoring of the production line were considered as the most important to maintain the product safety. In addition, D1 complied with 6 statements related to site protection, such as perimeter sealing (1), exterior lighting (2), factory built with sturdy materials (4), exterior opening windows, doors, and gates (9), access control (13), and presence of security alarms (17). Among these topics, access control was the most important for the 
participants, with a correlation of 0.793 . The respondents' perceptions of site protection and access control reflects the difficulty in preventing malicious attacks. In the private sector, severe actions to prevent attacks include identifying employees and controlling access to facilities (Hennessey and Busta, 2014).

Among all 37 statements considered important for the respondents of the dairy companies, the 3 largest correlations with D1 were item 23, which addresses the need to differentiate employees from different sectors of the company (0.947), item 27 , which shows the importance of employee satisfaction survey (0.911), and item 14, which regards the protection of end products (0.907). Furthermore, item 24, about employee awareness, also demonstrated a correlation with D1 (0.846). The implementation of different colors of the staff uniforms from different sectors within a company is a strategy for preventing malicious attacks, making it easier to identify individuals on the company premises (Hennessey and Busta, 2014). The education program should consist of acquiring the basic level of awareness on food defense, the implementation of prescribed procedures, and assessment methods for the identification and mitigation of potential risks (Bogadi et al., 2016). The potential for an employee to undertake sabotage could be highlighted in advance by other negative behaviors such as absenteeism, low morale and job satisfaction, stress, and poor performance. However, job satisfaction is considered the mediating factor (Manning, 2019). This was an important problem recently in Brazil, as 17 people were poisoned, and 1 person died after drinking beer contaminated with diethylene glycol. This problem was linked to an employee that was not satisfied with his employment in the company (Food Safety News, 2020).

The restriction to ingredient storage areas is a good prevention strategy in food protection, reducing the risk of contamination in raw materials (Hennessey and Busta, 2014), especially when these raw materials will be subjected to mixing and dilutions to make the end product. In fact, there was a correlation of 0.854 with item 12 , which corresponds to the attention in the storage of raw materials, and 0.907 with item 14, regarding the storage of the end product, demonstrating the awareness of dairy processors to these questions.

Item 18, which refers to the internal access control between areas, exhibited the lowest correlation (0.564) in $\mathrm{D} 1$, followed by item 5 (0.588), which corresponded with vehicle monitoring. Identifying and segregating the important areas may be an alternative to reducing intentional cross-contamination in dairy companies. According to Moerman (2018), contamination can occur with chemical agents such as oils, lubricants, ethylene glycol, and microbiological agents (such as Salmonella spp. and Escherichia coli). These contaminants may be present in laboratories, utilities, or waste and disposal areas. Item 25 , on the assessment of employee health as an important measure for food safety, completes the list of the 3 statements with the lowest association with the D1, with a value of 0.597 .

The second dimension was positively correlated with items $3,8,15,20,29,31,38$, and 39 . This result implies that the periodic inspection, controlling of employees and visitors, elaboration of writing procedures, emergency lighting system, quality control, and up-to-date emergency contact list as a preference to maintain the product safety are the main attributes in D2. A greater correlation of D2 with item 31 (0.828) was observed, which corresponded with the restriction of access to computers as a good practice for food defense. The PAS 96:2017 Guide (BSI, 2017) defines cybercriminals among attacker profiles, and how access control to the dairy data network is a strategic alternative within a food defense plan. The restriction of access to computers can reduce the risk of industrial espionage, which is often focused on commercial rivals for commercial purposes, aiming trade secrets, and intellectual property (patents, trademarks, recipes, copyrights, product formulations, processing techniques, among others; Manning, 2019). In most cases of espionage, employees disclose information through information technology systems (Bogadi et al., 2016).

The second highest correlation was observed for item 29 (0.817), which stated that the water treatment program increases product safety. Water treatment is fundamental in the control of chemical, physical, and microbiological hazards (Moerman, 2018), in addition to being a legal requirement in Brazil. Item 38, on the availability of an emergency contact list, exhibited the third-largest correlation (0.748). Maintaining the list may be a strategic decision for emergency actions to enable diagnosis, contamination notification, and recall of affected products (Frederickson, 2014).

Food defense principles can be implemented at all levels of the food chain to contribute to mitigation of risks in intentional contamination and food fraud, which can have a detrimental effect on human and public health, business, and the economy. The implementation of food defense can be required by federal law, as regulatory requirements for food defense or portions of food defense exist in many countries, such as the United States, European Union, New Zealand, and China, or by customer and supplier interactions throughout the food chain, as evidenced by the number of third-party certification audits requiring food defense be addressed (Manning et al., 2019). Many food companies require their suppliers to be certified to food safety system standards recognized by the Global Food Safety Initiative. Whereas food advocacy is an inevitable step to 
improve and strengthen the entire food safety system on a global scale, an insufficient number of countries have incorporated food defense principles into their legal frameworks (Bogadi et al., 2016).

With ever-changing global trade along the food supply chain, rising prices, and declining economies, greater diligence in defending food against deliberate contamination has been introduced for both economic and terrorist reasons. Initiatives include developing specific countermeasures to minimize or eliminate vulnerabilities, as well as developing practical solutions that enhance the ability to identify, contain, respond, and recover quickly from intentional contamination. These activities should encompass the entire global agricultural production system, from prefarm inputs to retail sales, food consumption, and public health system response (Busta and Kennedy, 2011).

The food defense plan (FDP) is the set of actions to prevent malicious attacks, including threat identification, risk analysis, and determination of control measures (Manning and Soon, 2016). Risk assessment should be conducted to assess the impact of identified threats, considering the likelihood of the occurrence and their severity, and control measures established accordingly (Bogadi et al., 2016). The FDP is operationalized through trained personnel who perform the standard operating procedures described in the company plan. The FDP can be assembled by a company team, which analyzes the results of the facility's vulnerability assessment, ranks the issues according to their importance to food defense, and develops preventive controls that are likely to protect against intentional contamination events (Huff, 2018). In July 2019, US FDA (2019) required a FDP for companies providing product into the US market. The rule was developed to address hazards that may be intentionally introduced to foods, including acts of terrorism, with the intent to cause widespread harm to public health. Food facilities significantly vulnerable to intentional adulteration are required to develop and implement an FDP based on the information provided on facility information, process and product description, vulnerability assessment, mitigation strategies, food defense monitoring procedures, food defense corrective action procedures, and food defense verification procedures (US FDA, 2019).

\section{CONCLUSIONS}

The overall perception of the Brazilian dairy processors regarding food defense was mainly related to the areas listed in the questionnaire, being external security, followed by personnel security, generalities and internal security. According to the obtained results, we suggest that actions related to food defense should be mainly focused on differentiating workers who are involved in activities related directly at the processing line and the protection of the dairy products, besides to the identification of unsatisfied employees through satisfaction surveys. Although food defense is not a legal requirement in Brazil, it has taken on an increasingly important role in Brazilian dairy food safety programs, as many of the Brazilian dairy producers would be responsible for meeting foreign regulatory requirements if their products are exported to those markets. To improve its implementation, documentary evidence assessment and dairy site visits are suggested to check the level of application of the FDP and the ability to react in the event of an incident.

\section{ACKNOWLEDGMENTS}

This study was financed in part by the Coordenação de Aperfeiçoamento de Pessoal de Nível Superior - Brasil (CAPES) - Finance Code 001, FAPERJ and IFRJ. The authors thank A. S. Sant'Ana, A.G. Cruz, and the Conselho Nacional de Desenvolvimento Científico e Tecnológico (CNPq, Grants \#302763/2014-7 and \#305804/2017-0). The authors state that they have no conflicts of interest.

\section{REFERENCES}

Abrantes, M. R., D. C. S. Campêlo, and J. B. A. D. Silva. 2014. Fraude em leite: Métodos de deteç̧ão e implicações para o consumidor. Rev. Inst. Adolfo Lutz 73:244-251.

Betancourt, R. S. 2017. Defesa Alimentar (Food Defense): Avaliação da aplicação da ferramenta CARVER + Shock na indústria do leite no Brasil. Pages 53-83. Dissertação (mestrado) - Faculdade de Zootecnica e Engenharia de Alimentos, Universidade de São Paulo, Pirassuninga, Brazil.

Bogadi, N. P., M. Banović, and I. Babić. 2016. Food defence system in food industry: Perspective of the EU countries. J. Verbr. Lebensm. 11:217-226. https://doi.org/10.1007/s00003-016-1022-8.

Brazil. 2018. Projeções do Agronegócio: Brasil 2017/18 a 2027/28 projeções de longo prazo da Agricultura, Pecuária e Abastecimento. Secretaria de Política Agrícola, Brasília, Brazil.

BSI (British Standards Institution). 2017. PAS 96:2017: Guide to protecting and defending food and drink from deliberate attack. Accessed Oct. 6, 2019. https://www.food.gov.uk/sites/default/files/ media/document/pas962017.pdf.

Busta, F. F., and S. P. Kennedy. 2011. Defending the safety of the global food system from intentional contamination in a changing market. Advances in Food Protection. NATO Science for Peace and Security Series A: Chemistry and Biology. M. Hefnawy, ed. Springer, Dordrecht, the Netherlands.

Carrillo, E., P. Varela, and S. Fiszman. 2012. Influence of nutritional knowledge on the use and interpretation of Spanish nutritional food labels. J. Food Sci. 77:H1-H8. https://doi.org/10.1111/j.1750 -3841.2011.02479.x.

EMBRAPA. 2018. Anuário Leite 2018: Indicadores, tendências e oportunidades para quem vive no setor leiteiro. Embrapa. Gado de Leite. Accessed Oct. 6, 2019. https://bit.ly/30vEVSn.

Food Safety News. 2020. Backer told to recall beer linked to poisoning in Brazil. Accessed 11/03/2020. https://www.foodsafetynews .com/2020/01/backer-told-to-recall-beer-linked-to-poisoning-in -brazil/. 
Fredrickson, N. R. 2014. Food Security: Food Defense and Biosecurity. Pages 311-323 in Encyclopedia of Agriculture and Food Systems. N. K. V. Alfen, ed.

Hennessey, M., and F. Busta. 2014. Public Health Measures. Food Defense: Prevention of Sabotage and Bioterrorism. Encycl. Food Saf. 4:68-70.

Henriques, A. R., and M. J. Fraqueza. 2015. Listeria monocytogenes and ready-to-eat meat-based food products: Incidence and control. Pages 71-103 in Listeria monocytogenes: Incidence, Growth Behavior and Control. Nova Science Publishers, New York, NY.

Huff, A. G. 2018. Food defense. Pages 652-656 in Encyclopedia of Food Chemistry Vol. I. P. Varelis, L. Melton, and F. Shahidi, ed. Elsevier, London, UK.

Lelieveld, H. L. M., M.A. Mostert, and J. Holah. 2005. Improving zoning within food processing plants. Pages 68-92 in Hygiene in Food Processing. Woodhead Publishing, Cambridge.

Maciel, E. S., L. K. Savay-da-Silva, J. S. Vasconcelos, J. A. Galvão, J. G. Sonati, D. Silva, and M. Oetterer. 2013. Application of exploratory factor analysis to assess fish consumption in a university community. Food Sci. Technol. 33:99-106. https://doi.org/10 .1590/S0101-20612013005000016.

Manning, L. 2019. Food defense: Refining the taxonomy of food defence threats. Trends Food Sci. Technol. 85:107-115. https://doi .org/10.1016/j.tifs.2019.01.008.

Manning, L., P. A. Luning, and C. A. Wallace. 2019. The evolution and cultural framing of food safety management systems-Where from and where next? Compr. Rev. Food Sci. Food Saf. 18:17701792. https://doi.org/10.1111/1541-4337.12484

Manning, L., and J. M. Soon. 2016. Food safety, food fraud, and food defense: A fast evolving literature. J. Food Sci. 81:R823-R834. https://doi.org/10.1111/1750-3841.13256.

Matzembacher, D. E., I. D. Carmo Stangherlin, A. L. Slongo, and R. Cataldi. 2018. An integration of traceability elements and their impact in consumer's trust. Food Control 92:420-429. https://doi .org/10.1016/j.foodcont.2018.05.014.

Moerman, F. Sr. 2018. Food defense. Pages 135-222 in Food Control and Biosecurity, Volume 16. A. Grumezescu, A.M. Holban, ed. Academic Press, Cambridge, MA.

Pacheco, M. H. S., S. P. Kuriya, C. S. C. Capobiango, T. C. Pimentel, A. G. Cruz, E. A. Esmerino, and M. Q. Freitas. 2018. Exploration of gender differences in bottled mineral water consumption: A projective study of consumer's perception in Brazil. J. Sens. Stud. 33:e12434. https://doi.org/10.1111/joss.12434.

Praia, E. F. S. S. 2017. Avaliação da implementação de requisitos de food defense em unidades industriais alimentares. Dissertação de mestrado. Universidade de Lisboa, Faculdade de Medicina Veterinária, Lisboa.
Rahnama, H., M. Fadaei, and S. Baghersalimi. 2017. Healthy food choice: Survey results from Iranian consumers toward antibioticfree chicken. J. Sens. Stud. 32:e12248. https://doi.org/10.1111/ joss.12248.

Sobhanifard, Y. 2018. Hybrid modelling of the consumption of organic foods in Iran using exploratory factor analysis and an artificial neural network. Br. Food J. 120:44-58. https://doi.org/10.1108/ BFJ-12-2016-0604.

Soon, J. M., S. C. Krzyzaniak, Z. Shuttlewood, M. Smith, and L. Jack. 2019. Food fraud vulnerability assessment tools used in food industry. Food Control 101:225-232. https://doi.org/10.1016/j.foodcont .2019.03.002.

Spink, J., P. B. Embarek, C. J. Savelli, and A. Bradshaw. 2019. Global perspectives on food fraud: Results from a WHO survey of members of the International Food Safety Authorities Network (INFOSAN). NPJ Sci. Food 3:12. https://doi.org/10.1038/s41538-019 -0044-x.

USDA. 2008. Guide to Developing a Food Defense Plan for Food Processing Plants. USDA, Washington, DC.

US FDA (Food and Drug Administration). 2009. CARVER + shock primer: an overview of the carver plus shock method for food sector vulnerability assessments. Accessed Dec. 12, 2009. https:// www.fda.gov/food/food-defense-programs/carver-shock-primer.

US FDA (Food and Drug Administration). 2014. Food Safety Modernization Act. USA: FDA. Accessed Oct. 6, 2019. http://www.fda .gov/food/guidanceregulation/fsma/ucm247548.htm.

US FDA (Food and Drug Administration). 2015. FSMA Final Rule for Preventive Controls for Human Food. Accessed Nov. 3, 2020. https://www.fda.gov/food/food-safety-modernization-act-fsma/ fsma-final-rule-preventive-controls-human-food.

US FDA (Food and Drug Administration). 2016. Mitigation Strategies to Protect Food Against Intentional Adulteration. Accessed Nov. 3, 2020. https://www.federalregister.gov/documents/2016/ 05/27/2016-12373/mitigation-strategies-to-protect-food-against -intentional-adulteration.

US FDA (Food and Drug Administration). 2018. Draft Guidance for Industry: Hazard Analysis and Risk-Based Preventive Controls for Human Food. Accessed Dec. 12, 2019. https://www.fda .gov/regulatory-information/search-fda-guidance-documents/ draft-guidance-industry-hazard-analysis-and-risk-based-preventive -controls-human-food.

US FDA (Food and Drug Administration). 2019. FDA Launches Updated Food Defense Plan Builder. Accessed Nov. 3, 2020. https: //www.fda.gov/food/cfsan-constituent-updates/fda-launches -updated-food-defense-plan-builder.

WHO. 2009. Codex Alimentarius: Food hygiene, basic texts. Fourth ed. World Health Organization, Geneva, Switzerland. 